\title{
Familias in the Heartland: Exploration of the Social, Economic, and Cultural Realities of Latino Immigrants
}

\author{
Melinda Lewis
}

\begin{abstract}
This survey of 957 Latino immigrant adults in urban and suburban communities in the greater Kansas City metropolitan area explores the migration experiences, employment contexts, family structures, and integration processes of an emerging and rapidly growing immigrant population. The study is an example of community-driven research, conducted by a nonprofit community development and immigrant rights organization in close partnership with local immigrant leaders.
\end{abstract}

\section{Methodology}

In August-September 2005, El Centro, Inc., a community immigrant rights organization, conducted a survey of the Latino immigrant community in the Kansas City area. This survey was designed in partnership with Latino immigrant leaders working with El Centro to advance the general public's understanding of immigrant concerns and enhance leaders' ability to respond to community needs. The sample involved 957 Latino immigrant adults living in the urban cores of Kansas City, Kansas, and Kansas City, Missouri and outlying suburban areas. The sampling technique was nonrandom, employing convenience, snowball, and strategic sampling strategies. The survey was completely anonymous, and most respondents completed it in Spanish.

\section{Population Characteristics}

Estimates of the size of the Hispanic/Latino population are notoriously inaccurate, due in large part to high per- centages of immigrants, high mobility, and the relatively new practice of including ethnicity in racial data. ${ }^{1}$ Still, the 2003 American Community Survey by the U.S. Census Bureau provides some guidance, particularly as the 2000 Census fades in utility. As an illustration of the limitations of the Census in capturing this population, only $18.1 \%$ of respondents in El Centro's 2005 survey report having participated in the 2000 Census. Notably, while Census participation was higher among those who arrived in the United States before 2000, it is still low for this group, at only $31 \%$. Of those who did not participate in the Census, $37 \%$ report that they were not yet in the United States in 2000, $45 \%$ lacked information, and $18 \%$ were afraid to participate due to their immigration status.

One of the most notable phenomena related to this most recent wave of immigrants to the United States has been suburbanization. Despite the lack of strong statistical evidence

\footnotetext{
1 Both "Hispanic" and "Latino" are terms used by researchers to describe those of Latin American descent, the target of this analysis. The author will primarily use "Latino," but other referenced sources may include "Hispanic."
} 
explaining the logic of geographic decision-making among survey respondents, there are several noticeable differences in the immigrant populations in urban and suburban communities. Immigrants in the nearby suburbs have spent considerably fewer years in the United States $(t=3.555)$, have higher levels of education in the country of origin $(t$ $=-3.945)$, spent shorter periods of time seeking work upon arriving in Kansas City $(t=2.774)$, have shorter commute times $(t=3.913)$, smaller households $(t=3.830)$, and shorter tenures in their homes $(t=2.610)$. This population diffusion creates particular challenges for social service providers, most of which are located in the urban core. Lack of reliable public transportation, community resistance to acknowledging changing demographics, and fewer resources for those struggling with poverty in general complicate efforts to meet these families' needs in the context of relative affluence.

The median number of years in the United States for respondents was $6(M=10.33)$. Most respondents' tenure indicates some time spent in another part of the country, as the median number of years in the Kansas City area was 4 $(M=5.31)$. These short tenures are significant for many reasons, including an increased likelihood of limited English proficiency and relative unfamiliarity with U.S. norms. The vast majority of respondents (86\%) are Mexican, which is also significant given the great differences in education levels, reasons for migration, and pre-migration experiences based on country of origin.

The survey population is considerably younger than the overall Kansas City area population and even younger than the Hispanic population, despite a methodology that excludes respondents younger than 16 . Sixty percent of the respondents are between the ages of 25 and 40 . This fact is likely related to the dynamics of migration, which tends to be an enterprise primarily undertaken by younger individuals. Respondents are significantly more likely to be married than are other adults in the Kansas City area, and much less likely to be widowed.

\section{Immigration Matters}

While the precise current legal status of respondents is unknown due to an intentional decision by the survey design team, $42.4 \%$ of the sample entered the United States with legal documentation and $57.6 \%$ did not. Those who entered with legal documents appear to be in some ways different from those who did not; they speak more English $(t=2.579)$ and have higher education levels in their country of origin $(t=5.542)$. However, their experiences upon arriving in Kansas City, including interactions with the labor market, are remarkably similar. Also notable is the fact that those who entered with legal documentation have significantly longer tenures in Kansas City than those who did not, likely reflecting both the relatively easier process in years past of gaining lawful admission to the United States, and families' eventual success in attaining lawful status.
Those who entered the United States with legal documents were more likely to come with family members (59\%) than to migrate alone (41\%). Demonstrating the strong link between immigration and family unity, $66 \%$ had family already living in the Kansas City area. An astounding $82 \%$ of respondents live in mixed-status families, where at least one family member has lawful immigration status and at least one family member does not. This finding obviously has tremendous implications, as it means that even those who have lawful immigration status are intimately affected by the tenuous nature of their family members' lack of status. On a daily basis, this manifests itself in terms of reduced eligibility for and utilization of public benefits, reluctance even by those lawfully present to interact with authorities, and, in many cases, family separation and dissolution. The December 2005 passage in the U.S. House of Representatives of H.R. 4437, which would have, among other things, redefined the crime of "alien smuggling" to include any humanitarian assistance rendered to an undocumented immigrant, highlighted this as an ethical issue for practitioners as well, as demonstrated by the presence of social service providers around the country at many rallies opposing H.R. 4437 in the spring of 2006.

Almost $83 \%$ of non-citizens in the sample reported that they plan to become U.S. citizens. This finding demonstrates a strong tendency towards naturalization, even for a population of recent immigrants with long waits ahead. Those who intend to naturalize have spent more years in the United States than those who do not, but this does not appear to be a strong factor $(t=2.441)$. English proficiency and years of education do not differ significantly between the two groups. The percentage that intends to naturalize corresponds closely, however, to the percentage intending to stay in the United States for at least the next 10 years (approximately 85\%). Only 78\% intend to stay in Kansas City for at least the next 10 years. Those respondents who intend to stay in Kansas City for at least the next 10 years are significantly older than those who do not $(t=$ 3.548). This finding is perhaps related to older respondents' reduced willingness to uproot again or their greater degree of connection to the area. Given the relationship between family mobility and the difficulty that children, in particular, have in adjusting to either environment, deeper exploration of what ties families to particular communities is important.

\section{Education}

While education levels for Hispanics of all ages and citizenship statuses are increasing, they still have the lowest formal educational attainment of any population subgroup. Perhaps even more concerning are analyses that, while earnings increase for Hispanics with higher education levels, they see relatively less payoff for their additional education than non-Hispanic Whites. For 
example, the average earnings gap for non-Hispanic White and Hispanic high school dropouts was only $\$ 442$ per year in 2002 , compared to $\$ 4,593$ for high-school graduates and more than $\$ 12,200$ per year for those with a bachelor's degree (U.S. Census Bureau, 2004a). This disparity, of course, affects Latinos' motivations for continued education and reflects larger barriers in their occupational and economic advancement.

An essential public policy question, then, relates to the factors that contribute to this relatively lesser return on educational investment. It is likely that all of the following factors play a role, to some extent: continued discrimination in the labor market, perceived lower quality of education in some of the schools where Latinos study, and lack of necessary relationships to leverage into opportunities for employment mobility. Service providers must pay attention to factors such as these, which are likely to impact Latino adolescents' orientation toward continued education. Especially in states with significant barriers to college for immigrant students, it is common to hear Latino students complain about the futility of their studies and their desire to trade possible future gains for a paycheck today.

\section{Language}

Census data reveal, and our survey data reinforce, the presence of significant language barriers in Latino immigrant communities in the area. The Census Bureau defines a "linguistically-isolated" household as one in which no member 14 years of age or older speaks English at least "very well." Twenty-two percent of Spanishspeaking households in Kansas are linguistically isolated, $14 \%$ in Missouri, $15 \%$ in Jackson County (Missouri), $14 \%$ in Johnson County (Kansas), and 16\% in the Kansas City area (U.S. Census Bureau, 2005). These figures are important, obviously, because English proficiency impacts immigrants' daily lives and their imprint on the communities in which they live.

Importantly, while the number of years in the United States is not significantly correlated to a respondent's English proficiency, the number of years in the Kansas City area is, suggesting that the metropolitan area is a better context in which to promote English language learning than other parts of the country $(r=.246)$. Male survey respondents are significantly more proficient in English than female respondents $(t=3.082)$. This has been found in other studies of Latino immigrants around the country and is often believed to be related to men's greater experiences of labor market participation, somewhat longer tenures as migrants, and exposure to native English speakers. It raises an important question for service providers about how to increase English proficiency in immigrant women, particularly given women's important roles as the primary teachers for their children, all of whom will need to master English to succeed.

\section{Employment and Unemployment}

The unemployment rate for the Kansas City MSA was 5\% in August 2005 (Bureau of Labor Statistics, September 2005). The rate for survey respondents was remarkably similar, with $5.9 \%$ unemployed. This finding suggests that Latino immigrant respondents have a fairly similar labor market experience, in terms of weathering economic cycles, as other workers in the metropolitan area. As shown in Table 1, Latino immigrants are working in nearly every part of the local economy, although the same industries densely populated with immigrants around the United States feature most prominently in local immigrants' labor experiences as well.

\section{Finding Work}

The median amount of time immigrant respondents needed to find employment upon arriving in the Kansas City area was one month, and men needed significantly less time to find work after arriving in Kansas City than women $(t=-6.271)$. This finding is likely related to the occupations that are most heavily concentrated with immigrant workers and men's greater appeal to employers in many of these, including construction, landscaping, and general labor. And, again, possession of documents enabling one to work legally does not have an apparent impact on the length of time needed to find work, nor is there any significant correlation between one's English proficiency and the amount of time needed. There is a statistically significant correlation between years in the Kansas City area and the amount of time needed to find a job initially, indicating that earlier immigrants to the area faced greater difficulties in finding employment than today's arrivals $(r=.150)$. Upon closer analysis, this trend may reflect the reduction in discrimination in the labor market faced by Latino job seekers, the growing economic strength of the Midwest region and its relative avoidance of serious economic downturn in the

TABLE 1. Occupational Distribution for Survey Respondents by Gender

\begin{tabular}{lrr}
\hline Occupation & MALES & FEMALES \\
\hline Unemployed & $3.5 \%$ & $8.1 \%$ \\
Construction & $29.0 \%$ & $2.0 \%$ \\
Retail & $5.0 \%$ & $8.0 \%$ \\
Landscaping & $5.0 \%$ & $0.8 \%$ \\
Hospitality & $19.0 \%$ & $33.0 \%$ \\
Janitorial & $10.0 \%$ & $20.0 \%$ \\
Manufacturing & $11.0 \%$ & $9.0 \%$ \\
Labor & $9.0 \%$ & $2.0 \%$ \\
Clerical & $1.2 \%$ & $4.0 \%$ \\
Health Care & $1.2 \%$ & $5.0 \%$ \\
Maintenance & $4.0 \%$ & $0.0 \%$ \\
Professional & $0.4 \%$ & $0.8 \%$ \\
Agriculture & $1.2 \%$ & $2.0 \%$ \\
\hline
\end{tabular}

Note: Percentages do not equal 100 due to some of the respondents not actively seeking work. 
TABLE 2. Wage Comparisons for Selected Industries

\begin{tabular}{lcc}
\hline OcCUPATION/INDUSTRY & $\begin{array}{c}2004 \\
\text { AvERAGE WAGES }^{\mathrm{a}}\end{array}$ & $\begin{array}{c}\text { MEDIAN WAGE } \\
\text { FOR RESPONDENTS }\end{array}$ \\
\hline Retail & $\$ 9.26$ & $\$ 7.78$ \\
Mechanic & $\$ 21.82$ & $\$ 8.00$ \\
Manufacturing & $\$ 21.26$ & $\$ 9.00$ \\
Landscaping & $\$ 10.00 *$ & $\$ 9.50$ \\
Laborers & $\$ 14.58$ & $\$ 8.00$ \\
Cooks & $\$ 10.56 * *$ & $\$ 8.00$ \\
Janitors & $\$ 11.75$ & $\$ 8.00$ \\
\hline
\end{tabular}

${ }^{a}$ Bureau of Labor Statistics (2005b). U.S. Department of Labor. National compensation survey. Retrieved July 20, 2005. Available from: http://data.bls.gov

* Only 2003 data available for this occupation.

** Only 2003 data available for this occupation.

TABLE 3. Benefits Received by Respondents, Compared by Industry

\begin{tabular}{|c|c|c|c|c|}
\hline CAtEgory & $\begin{array}{l}\text { PAID SICK } \\
\text { LEAVE }\end{array}$ & $\begin{array}{c}\text { PAID } \\
\text { VACATION }\end{array}$ & $\begin{array}{c}\text { MEDICAL } \\
\text { CARE }\end{array}$ & $\begin{array}{l}\text { RETIREMENT } \\
\text { PLANS } \\
\end{array}$ \\
\hline All Private Industry ${ }^{a}$ & $59 \%$ & $77 \%$ & $53 \%$ & $50 \%$ \\
\hline Full-time & $70 \%$ & $90 \%$ & $66 \%$ & $60 \%$ \\
\hline Part-time & $24 \%$ & $35 \%$ & $11 \%$ & $20 \%$ \\
\hline Manufacturing & $49 \%$ & $85 \%$ & $69 \%$ & $63 \%$ \\
\hline Service & $37 \%$ & $58 \%$ & $24 \%$ & $22 \%$ \\
\hline $\begin{array}{l}\text { Survey respondents } \\
\text { Full-time ( } 40+\text { hours/week) }\end{array}$ & $13 \%$ & $35 \%$ & $19 \%$ & $11 \%$ \\
\hline employed respondents & $29 \%$ & $79 \%$ & $43 \%$ & $25 \%$ \\
\hline
\end{tabular}

recent economic softening, greater networks of support for immigrants seeking jobs, and employers' positive experiences with immigrant employees.

Despite relative ease in finding work initially, there appears to be little job stability for immigrant workers. Only $29 \%$ of respondents are still working in the same job that they first obtained upon their arrival. Pursuit of better compensation was the driving force most commonly cited for job change, although many factors play a part in the dynamic work lives of local Latino immigrants, including exploitation, adverse immigration action, abrupt termination, lack of reliable transportation, and childcare needs.

\section{Wages}

Table 2 compares the average wages for selected occupations and industries in the survey area with the median wages of survey respondents.

The median hourly wage for all employed survey respondents across occupations was $\$ 8.50$. This equates to approximately $\$ 17,000$ per year for a full-time employee. Given respondents' reported earnings, it is perhaps surprising that only $40 \%$ report sacrificing food, medical care, housing, or utilities within the past 12 months due to inadequate income. This figure is slightly higher in suburban communities, at $43 \%$, but still much lower than the rates observed in previ- ous agency studies. Interestingly, while the cost of living is notably higher in the suburbs than in the other survey jurisdictions, so are respondents' wages. In Kansas City, Kansas, and Kansas City, Missouri, the median hourly wage is $\$ 8.25$, and monthly income is $\$ 1,500$, while these figures are $\$ 8.75$ and $\$ 1,600$, respectively, in the suburbs. These differences are significant $(t=1.928)$, indicating that there is at least some wage premium for those in more expensive suburban communities. There were no statistically significant differences in earnings based on gender. As stated elsewhere in this report, there were no significant relationships between respondents' hourly wages and their tenure in either Kansas City or the United States, their education level in their country of origin, or their English proficiency. These findings suggest that other factors determine wages and that current strategies to increase human capital among immigrant workers in order to increase their incomes may be less than successful.

\section{Employee Benefits}

As Table 3 illustrates, while survey respondents see lower rates of benefit offerings than other workers in some industries, it appears that their greater vulnerability in the labor market stems both from individual factors related to their own ability to compete (perhaps discrimination based on citizenship status or lack of English proficiency), as well as to structural characteristics of the occupations in which they work (such as part-time status, or concentration in low-benefit industries). Because employer-offered benefits are the primary source of health insurance, retirement savings, and other supports that help families to weather economic difficulties and prepare for the future, the vulnerability of respondents' families in these areas is certainly concerning.

Slightly more than half $(55.5 \%)$ of respondents who are offered employee benefits report that they do not use all of those offered. Respondents gave several reasons for not using benefits: lack of work authorization and fear of reprisal (29\%), inability to afford the employee contribution (27\%), lack of knowledge about benefits (29\%), and perceived lack of need for the benefits offered (16\%). Clearly, there are many non-immigrant employees in the labor force who also fail to utilize all of the benefits for which they are eligible, but, because at least some of the barriers referenced by survey respondents specifically relate to employees' immigration statuses and/or limited English proficiency, it is obvious that immigrant workers face even greater hurdles.

Given the low level of benefit offerings, these selfreported utilization figures are particularly concerning. As social service providers seek to build safety nets to support the families with whom they work, addressing this significant gap becomes an essential justice issue. Where workers are not offered health care or other benefits, or are discouraged from utilizing them, practitioners will face 
even greater hurdles in helping families to survive crises of injury, temporary unemployment, or family illness.

\section{Work Conditions and Exploitation}

Almost $16 \%$ of respondents report that they have been injured on the job, to the extent that they could not work for a period, at some point during their careers in the United States-a statistic that is much higher than the overall serious injury rates even in occupations considered relatively dangerous. This is also notable given their rather short work careers in the United States, indicating a frequency of injury that bodes very poorly for their future safety. Also of concern is the figure of only $64 \%$ of respondents classifying their work environments as "safe." Additionally, almost $11 \%$ of respondents reported that they have, at some point, had difficulty obtaining a final paycheck from an employer upon changing jobs. Almost $17 \%$ have worked without pay in the United States. Almost 35\% of employed respondents reported that they are not paid overtime for hours more than 40 that they work in a week. These data, collectively, reveal pervasive violations in the labor laws that are supposed to protect the rights of all workers, including immigrant workers, to be paid lawfully for the hours worked. They also illustrate the challenges that immigrant workers face in exercising these rights, particularly since the Supreme Court's 2002 Hoffman Plastics decision, which limited undocumented workers' access to remedies for labor violations.

\section{Finances}

Seventy-five percent of survey respondents reported that they send money, at least occasionally, to family members in their country of origin. Thirty percent send at least once per month. Those sending more regularly send significantly more, on average, in each remittance ( $\$ 263$ versus $\$ 172, t=-3.913)$. The median amount sent by those who remit is $\$ 150$ each time. The median cost for each remittance is $\$ 10$, although costs range from $\$ 2$ to $\$ 30$. While these remittances are obviously quite significant in terms of net economic activity, they also have great importance at the individual and family level, where financial responsibilities to those in the country of origin become part of the calculus that impacts local consumption and savings patterns, as well as the dynamic of financial stress that weighs so heavily on both low- and moderate-income families.

Only $31 \%$ of survey respondents, compared to $59.2 \%$ of U.S. families, report saving money in the previous year (Aizcorbe, Kennickell, \& Moore, 2003). For survey respondents who report saving, $36 \%$ are saving for liquidity, $21.4 \%$ for education, $32.4 \%$ for homeownership, and $10.1 \%$ for retirement. While there is no noted relationship between hourly wages and savings behavior for immigrant respondents, household monthly incomes for savers are
TABLE 4. Comparison of Families Without Bank Accounts ${ }^{\mathrm{a}}$

\begin{tabular}{lr}
\hline TYPE OF FAMILY & PERCENTAGE WITHOUT A BANK ACCOUNT \\
\hline All U.S. Families & $12.7 \%$ \\
Families of Color & $22.0 \%$ \\
Non-Hispanic White Families & $5.0 \%$ \\
Families With Incomes in the Lowest Quartile & $31.0 \%$ \\
Latino Immigrants in the U.S. $^{b}$ & $50.0 \%$ \\
Survey Respondents & $52.0 \%$ \\
\hline
\end{tabular}

${ }^{a}$ Aizcorbe et al., 2003

b IADB, 2005

significantly higher than for non-savers ( $\$ 2,076$ vs. $\$ 1,635$, $t=4.057$ ), and there is a significant correlation between monthly income and the amount of savings $(r=.296)$. This demonstrates, of course, that monthly income is more predictive of disposable income available for savings than one's hourly wage. The median amount saved by all savers was $\$ 1,000$, and the mean was $\$ 3,338$.

Table 4 shows the percentage of survey respondents in various family types who do not have bank accounts. Among those who do not have bank accounts, over 55\% cash their checks at a retail outlet. Using survey figures on pay, frequency, and average wages, and assuming an average cost of $5 \%$ for check-cashing, this activity generates at least $\$ 150,000$ per year among the survey population in check-cashing fees. Approximately $22 \%$ cash their checks at a bank, $10.2 \%$ have someone else cash the checks for them, and $12.2 \%$ are paid in cash.

\section{Children}

Because the children of immigrants represent one of the greatest contributions and challenges of immigration, an important component of this survey relates to respondents' children and their needs, hopes, and gifts. Fifty-six percent of respondents have children, and the median number of children in each family is 2 , although some households report as many as 10 children. The average number is 2.47 , reflecting family sizes fairly consistent with non-Hispanic households in the Kansas City area and much lower than the figures often reported for new immigrants. Given the age of the adult respondents, though, it is likely that many will continue to build their families.

Almost $90 \%$ of respondents indicate that they plan to send their children to college. There were significant differences in tenure in Kansas City $(t=3.114)$ and English proficiency $(t=3.161)$ for those responding positively to this item and very slight differences in parents' educational level $(t=1.222)$ and monthly income $(t=1.842)$. These findings represent another area where stereotypes about Latino immigrant parents are inconsistent with reality and demonstrate an opportunity for service providers to serve an important advocacy role-helping families to navigate resources leading to educational opportunities and informing the general public about the real nature of immigrants' orientation toward higher education. Only 
$36 \%$ of respondents reported knowledge of legislation passed in Kansas in 2004 that makes some immigrant Kansas high school graduates eligible for instate tuition at public colleges and universities. This illustrates the need for increased outreach and information dissemination, so that all eligible families can take advantage of this opportunity, particularly given the orientation toward higher education demonstrated here.

For survey respondents, the median amount paid for childcare is $\$ 60$ per week, equating to $16 \%$ of respondents' median monthly income and $\$ 3,100$ per year, if children attend full time. Notably, there were no significant differences in the average costs paid for center-based versus home-based childcare by respondents $-\$ 66$ per week compared to $\$ 61$ per week. Obviously, this raises important questions about the quality of care in formal settings and in family-based care arrangements and points to the importance of exploring affordable, high-quality options for low-income families. It also suggests that cost differentials are not the only, or perhaps not even the primary, reason that immigrant children are less likely to be in childcare centers, but, rather, that lack of knowledge about resources, cultural barriers, or uncertainty about eligibility may play a role. Service providers should help immigrant parents to research available childcare options, work with childcare providers to develop culturally-appropriate programming and marketing, and advocate for quality standards in both home and center-based care so that parents can make informed decisions.

\section{Domestic Violence and Mental Health}

Estimating the incidence of domestic violence within any community is difficult due to inconsistent reporting and the stigma associated with family violence. Accurately determining the incidence of domestic violence within an immigrant population is further complicated by language barriers that separate victims from service providers, different cultural norms governing relationships, and fear of law enforcement. While many experts suggest that domestic violence rates are higher within immigrant populations, for a variety of cultural, socioeconomic, and contextual reasons, estimates range widely. Approximately $11 \%$ of respondents report that they or a family member had been abused by a relative. For women, this figure was $15 \%$, and divorced women reported the highest rate of experience with domestic violence, at 33\%. In Kansas City, advocates for immigrant survivors of domestic violence are attempting to address this problem in a variety of ways, including training for law enforcement in Latino cultural norms, establishment of immigrant-friendly procedures at shelters, support for peer-to-peer support among survivors, and faith-based outreach to potential victims.

Accurately determining the prevalence of mental illness in any community is challenging, often necessitating dependence on self-reporting, with its associated methodological limitations. It is also complicated in communities with little access to mental health care, given the need for diagnosis. Still, estimates are that $27.7 \%$ of Hispanics in Kansas, compared with $35.2 \%$ of Hispanics in the United States, reported poor mental health status within the past 30 days (Kaiser Family Foundation, 2005). Several studies have also documented, for Latino immigrants, apparent increases in risk of mental illness with longer tenures in the United States (Duran, 1995), although survey data do not confirm this same relationship. Approximately $25 \%$ of the respondents in the survey sample have experienced a mental illness; $88 \%$ of these reported depression and $12 \%$ an anxiety disorder. This looks quite different based on gender. Over $30 \%$ of female respondents report suffering from a mental illness, with $92 \%$ of those reporting depression. By comparison, only $19 \%$ of men report a mental illness, and their symptoms display a different pattern, with $60 \%$ reporting depression and $40 \%$ anxiety. Access to mental health care is limited for many Latinos, but a relatively high $56 \%$ of survey respondents report receiving appropriate, affordable mental health services to address their particular needs.

\section{Health Status}

Health disparities continue to plague minority communities in the United States, with people of color experiencing disproportionate rates of uninsurance as well as higher rates of many chronic conditions. In 2000, only $62 \%$ of Latinos under age 65 and only $60 \%$ of those of Mexican origin were covered by health insurance (Centers for Disease Control, 2002). In Kansas, $16 \%$ of Hispanics under age 65 participated in Medicaid in 2003, compared with $22 \%$ of Hispanics nationwide and $24 \%$ of all Kansas children (Kaiser Family Foundation, 2005; American Academy of Pediatrics, 2005). Slightly more than $35 \%$ of the sample have a family member in Medicaid or a children's health insurance program. This figure seems high upon first consideration, but not when considered in light of the low median income levels, which place the majority of respondents within income eligibility guidelines, and given the context of low coverage levels of employer-provided health care. Taken collectively, these facts compromise access to health care for Latinos, particularly the foreign-born.

Only 70\% of Latinos of Mexican origin ages 18 and older have a source of ongoing health care, compared to over $85 \%$ of the non-Hispanic White population (CDC, 2002). Survey respondents indicate similar barriers, with almost $44 \%$ reporting that they do not always receive needed medical care. In the survey sample, those who reported not regularly receiving medical care had significantly lower monthly incomes than those with regular access $(r=2.694)$. Not surprisingly, then, financial constraints are the most common culprit in restricting respondents' 
access to medical care. Almost $82 \%$ of those without regular access to medical care cited lack of insurance and lack of money for out-of-pocket expenses as the barrier. Less common were concerns about lack of immigration authorization, unfamiliarity with medical resources, and limited English proficiency.

Health status suffers as a result of limited access to care. More than $40 \%$ of survey respondents rate their health as "fair" or "poor." As one would expect, there is a strong correlation between poor health status and advanced age $(r=.208)$. Chronic diseases also impact Latino communities disproportionately. More than $17 \%$ of survey respondents report that they have a chronic disease that interferes with their daily functioning. There were no significant correlations between income (hourly wage or monthly income) and health status for survey respondents. Those with health insurance provided through their employers enjoyed comparatively better health status, but it is obviously difficult to determine the direction of this correlation. Only $1 \%$ of those with employer-provided health insurance, for example, reported "poor" health status. While this could be because the availability of health insurance affords one greater access to medical care, and therefore fewer ongoing health problems, it could also be that those with poor health to begin with are out of the full-time labor market, and therefore are less likely to have insurance offered.

\section{Housing}

There is evidence that survey respondents are much more mobile in their housing arrangements than the general population. Figure 1 illustrates the housing status of survey respondents, by county of residence. Individuals who report contract for deed arrangements are particularly vulnerable to fraud, as they essentially rent-to-own their homes, with the only sometimes explicit understanding that they will become owners upon paying the equivalent of the principal and interest. The median tenure in the current dwelling was 1.5 years for survey respondents, with an average of almost 3 years in the same home, while $80 \%$ of households in the Kansas City area were in the same house 12 months prior to the survey. Average household size was 2.42 individuals for the general population in the Kansas City metropolitan area, compared with 3.05 for Hispanic households (U.S. Census Bureau, 2004b). For the survey sample, the median household size was 4 individuals, while the average was 3.85 . Almost $18 \%$ of survey respondents report that a non-relative lives with them. There were no significant correlations between respondents' household size and monthly incomes or wages, years in the United States or in Kansas City, tenure in the home, or housing cost. However, women have significantly larger household sizes $(t=-2.019)$, and there are significant correlations between household size and education level $(r=-.085)$, age $(r=-.162)$, and number of children in the family $(r=.432)$. These statistics contradict the idea of immigrant males living in large households of unrelated individuals and reflect similar trends to those seen in the general population.

The median amount spent on monthly rent and utilities by survey respondents was $\$ 750$. Not surprisingly, these figures were significantly higher in suburban Johnson County than in either of the urban areas ( $\$ 828$ to $\$ 684$ for total housing costs, $t=2.560$ ). Given median incomes of $\$ 1,500$ per month, it is clear that many respondent households are spending far more than $30 \%$ of their income on housing. Approximately $22 \%$ of renters report that they do not have a rental contract governing their housing arrangement. Perhaps not surprisingly, then, almost $29 \%$ report that their landlord fails to make needed repairs and/or perform basic maintenance. Those without rental contracts are much more likely to report deferred/denied maintenance (52\% compared to $24 \%$ of those with contracts). Lack of a rental contract does not appear to spur housing turnover, however, as there is no significant difference in housing tenures for those with and without contracts.

\section{Interactions With Society}

Slightly more than $9 \%$ of respondents report having been the victim of crime in the area where they currently live. Given that crime is usually reported based on arrests or incidents, rather than rates of victimization, an exact comparison to criminal activity in the larger community is difficult, but it appears that this is at least somewhat higher than victimization rates in most of the metropolitan area. If this is true, then the information presented here is even more alarming. Almost $27 \%$ of respondents reported that they would not call the police even if they were the victim of a crime. Those citing unwillingness to contact police were somewhat younger than those without such reluctance, although this difference is not very significant $(t=1.230)$. Men $(28.8 \%)$ are more reluctant

Figure 1. Respondents' housing status, by county of residence.

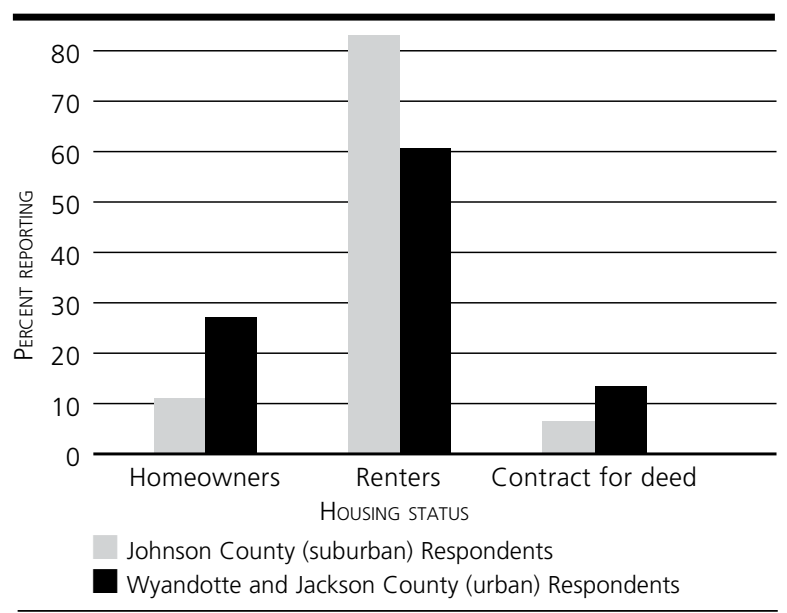


FIGURE 2. Respondents' experiences with discrimination in the Kansas City area.

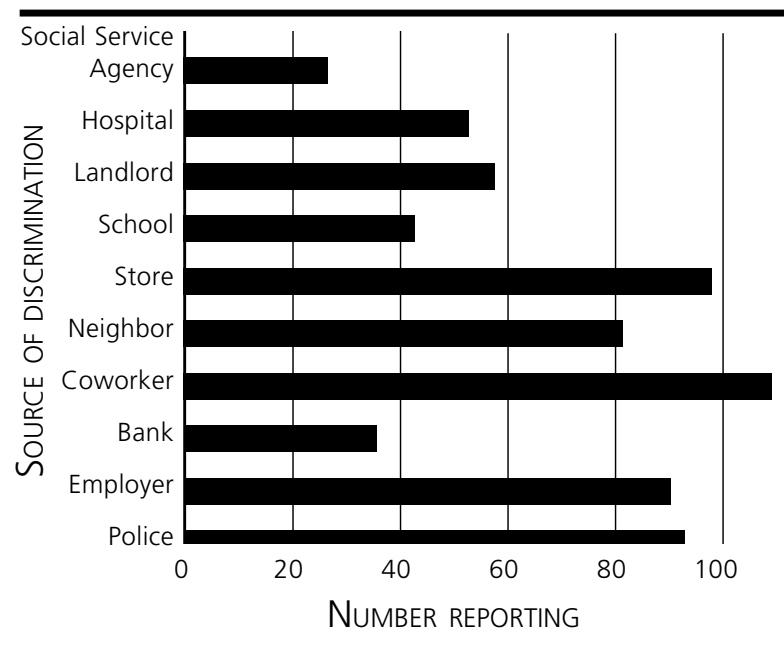

to contact the police than women $(25.7 \%)$. Clearly, this speaks to a need for coalition-building, as service providers seek to facilitate communication between vulnerable immigrant communities and the officers charged to serve them. It is also important to increase the accountability of law enforcement to communities of color, who have long expressed concern about disparate treatment.

Thirty-one percent of respondents report having experienced discrimination in the Kansas City area, with workplaces noted as the most common sources of such treatment. Figure 2 illustrates the most common sources of discrimination for survey respondents. The percentage of respondents claiming discrimination shows little change from past years' surveys; $29 \%$ in 2004 and 32\% in 2003 reported discrimination.

One of the areas of exploration in this study relates to respondents' perceived needs for additional community services and supports. This year, most prominent were concerns about expanded early childhood education options, including flexible and extended childcare hours and infant care; computer training, particularly with an employment focus; parenting groups designed to help parents cope with adolescence and special needs children; cultural programming, particularly to introduce children to native cultures; and expanded health services. Service providers, including those on the front lines, can play important roles in advocating for increased funding for these priorities, adaptation of existing programs to meet new community demographics, and collaboration among agencies to better fill gaps in services.

\section{Policy Recommendations}

El Centro seeks to use these data to inform policymakers about the characteristics, opportunities, needs, and challenges of the Latino immigrant population in our area.
From this year's report, several policy priorities emerge as offering particular promise in positively addressing what this community presents.

\section{Comprehensive Immigration Reform}

The large percentage of respondents living in mixedstatus families, as well as the many ways in which lack of lawful immigration status impacts respondents' ability to survive and thrive in the United States, point to the need for significant changes in our immigration system. Perhaps even more compelling, however, is the demonstration of strong demand for immigrant labor and the significant desire for integration into the local community and, indeed, U.S. society. Immigration reform that respects immigrant workers' rights, reunites families, and redeems the American Dream of a path toward citizenship is possible, and such legislative change would be the single most significant reform affecting the lives of these survey respondents and, by extension, the fabric of the communities in which they live and work.

\section{Improving Health Care Coverage}

The significant number of respondents lacking health insurance coverage and often access to health care is a concern not only for these respondents and those organizations with which they interact regularly, but also for all who live within the same communities, given the likely public health impacts of this situation. The Immigrant Children's Health Improvement Act (ICHIA) would restore lawful permanent resident children and pregnant women's eligibility for Medicaid and state children's health insurance programs, which was stripped from them in 1996. To address the issue of lack of health care coverage more broadly, however, we must tackle the large numbers of employers who are failing to provide affordable health insurance to even their full-time immigrant employees. A mixture of tax incentives and perhaps mandatory coverage guidelines would serve to help our current employer-based health care system meet the needs of these employed immigrant families who, despite their significant contributions to the economy, find themselves very vulnerable in terms of securing health care.

\section{Additional Investment in English Acquisition and Integration Programs for New Immigrants}

The communication barriers caused by limited English proficiency among new immigrants perpetuate divisions within communities, keep immigrants from advancing and integrating into their new environments, and foster dissension. There is an evident desire on the part of immigrants to learn English, yet there are limited resources to provide instruction. There are also only a few sporadic programs to orient new immigrants to the legal, social, and cultural norms of their new home, and the inevitable clashes are dealt with only intermittently as well. Federal 
funding for such programs would demonstrate that we are serious about immigrants being our new neighbors, not only our workers, and would help to guarantee that the current wave of immigration is as successful as those that have shaped our nation in the past.

\section{Workforce Housing and Public Transportation}

Many immigrant respondents live and work in different communities, often because they cannot afford to live near where the greatest employment opportunities are located. To address this phenomenon and the related issues of job absenteeism, reduced quality of life, and greater traffic congestion, we need to explore, as a metropolitan area, strategies for providing affordable workforce housing in our strongest economic areas and reliable, convenient public transportation to reduce reliance on automobile travel. Some businesses have aggressively pursued similar approaches themselves, providing transportation from urban centers to their suburban businesses and sponsoring employer-assisted housing programs to reduce turnover, but it is only with public investment that we can see such promising initiatives taken to a larger scale.

\section{Public Investment in Early Childhood Education Services}

We know that our children are our greatest resource and that the earliest years of life are very important in shaping a child's future educational attainment and life success. Therefore, we must follow the lead of nearly every other developed nation and invest in a universal early-childhood education system that will prepare young children for academic success, relieve parents of the stress of finding high-quality, affordable childcare, and extend our commitment to education from preschool through higher education. Cost-benefit analysis clearly indicates effectiveness, and we already have good models for what works in early childhood learning.

\section{Conclusion}

While there are obvious limitations in terms of the degree to which these data can be generalized beyond the Latino immigrant population in the Kansas City area, this study is important in that it represents one of the few communitydriven attempts to quantitatively examine the migration experiences, work environments, family structures, and future aspirations of an emerging and rapidly-changing Latino immigrant population. El Centro, Inc. owes a deep debt of gratitude to the immigrant men and women who so generously share their experiences with us each year in our sincere attempt to better understand, and therefore better represent and respond to, the needs and the goals of Latino immigrants in our communities.
Obviously, this analysis raises as many questions as it answers, and additional research is certainly needed, particularly to examine other immigrant groups to look for differences and commonalities in their experiences, and to explore, over time, how immigrants' experiences in the area evolve. It is our hope that this information will bring additional resources to work with immigrants, a greater respect for immigrants and the challenges they face, and a common commitment to promoting a society with fair opportunities for all who call our communities home.

\section{References}

Aizcorbe, A., Kennickell, A., and Moore, K. (2003). Recent changes in U.S. family finances: Evidence from the 1998 and 2001 survey of consumer finances. Federal Reserve Board. Retrieved August 16, 2005, from http://www.federalreserve.gov/pubs/oss/oss2/2001/scf2001home.html

American Academy of Pediatrics (July 2005). Kansas Medicaid facts. Retrieved August 16, 2005 from www.aap.org

Bureau of Labor Statistics (2005a). U.S. Department of Labor employee benefits survey. Retrieved July 20, 2005, from http://data.bls.gov

Bureau of Labor Statistics (2005b). U.S. Department of Labor national compensation survey for Kansas City, MO-KS MSA. Retrieved July 20, 2005 from http://data.bls.gov

Bureau of Labor Statistics (September 2005). Regional and state employment and unemployment. Retrieved July 20, 2005, from http://www.bls.gov/news.release/pdf/laus.pdf

Centers for Disease Control. (2002). A demographic and health snapshot of the U.S. Hispanic/Latino population. Retrieved August 16, 2005, from http://www.cdc.gov/NCHS/data/hpdata2010/chcsummit.pdf

Duran, D. (1995) Impact of depression, cultural determinants, psychosocial factors and the patient/care-provider relationship on somatic complaints of distressed Latinas. Unpublished doctoral dissertation, University of Denver.

Federal Reserve Board. (2001). 2001 survey of consumer finances. Retrieved August 16, 2005, from: http://www.federalreserve.gov/ pubs/oss/oss2/2001/scf2001home.html

Inter-American Development Bank (2005). Sending money home: Remittances to Latin America from the U.S., 2004. Available from: http://www.iadb.org/mif/v2/files/map2004survey.pdf

Kaiser Family Foundation (2005). Kansas State Profile. Retrieved August 16, 2005, from http://www.statehealthfacts.org/cgi-bin/healthfacts. cgi? action $=$ profile $\&$ area $=$ Kansas $\&$ welcome $=1 \&$ category $=$ Health + Status

U.S. Census Bureau (2004a). Educational attainment in the United States: 2003. Retrieved July 20, 2005, from http://www.census.gov/prod/2004pubs/p20-550.pdf

U.S. Census Bureau (2004b). Housing vacancies and homeownership, Annual statistics: 2004. Retrieved August 17, 2005, from http://www. census.gov/hhes/www/housing/hvs/annual04/ann04t20.html

U.S. Census Bureau (2005). 2003 American community survey summary tables. Retrieved July 20, 2005, from http://factfinder.census.gov/ servlet/DatasetMainPageServlet?_program=ACS\&_submenuId=\&_ lang=en\&_ts

Melinda Lewis, LMSW, was director, Policy Advocacy and Research, El Centro, Inc. Correspondence regarding this article may be addressed to melindaklewis@gmail.com or University of Kansas, School of Social Welfare, 12600 Quivira Road, Overland Park, KS, 66213.

Manuscript received: January 26, 2006

Revised: May 1, 2006

Accepted: May 5, 2006 